assured future editions, will remain a fitting tribute to him. Despite the plethora of antibacterial substances introduced recently into clinical use, the authors have been able to include most of them in this volume, as well as up-dating those parts of the book dealing with more general matters such as mechanisms of action and drug resistance. Its success is assured.

\section{Bladder Cancer. Principles of Combination Therapy.}

By R. T. D. Oliver, W. F. Hendry and H. J. G. Bloom. Pp. xix +326 , illustrated. Butterworths, London, 1981. $£ 25.00$.

This book stems primarily from the papers presented at an Institute of Urology workshop on 'New Approaches to the Treatment of Superficial and Invasive Bladder Cancer', held in July 1979: it has been meticulously edited by a medical oncologist (R. T. D. Oliver), a urologist (W. F. Hendry) and a radiotherapist $($ H. J. G. Bloom) and provides a comprehensive review of the background of experience upon which further practice and research must be built. The format is still a collection of individual contributions rather than a synthesis, which makes for difficult reading, and one longs for a summing up. However, rapidly changing viewpoints and hotly contested assertions rule out any meaningful distillation of wisdom at this stage. What investigators and innovators need is a ready source of information on results so far obtained, and this is what the book provides.

The accent is on combination therapy, using at least 2 modalities of treatment. While we are considering the combination of surgery and radiotherapy, we are on relatively familiar ground and articles emanating from the Royal Marsden and from the London Hospital give a clear picture of the state of the art: but when chemotherapy is added to the combination, we are in new territory and the possible permutations would leave even the football pool addicts at a loss. It is no wonder we have developed a special breed of oncologist to cope with this polypharmacy. Many will be relieved to know that treatment by multiple drugs has little advantage over cisplatinum alone, but there is little other hope given us for increasing simplification of drug regimes.

It is of course regrettable that tumour staging has progressed on parallel lines but with different terminology on the 2 sides of the Atlantic and the abbreviations familiar enough to those immersed in the problems, will cause the general reader some irritation. It does take time to assimilate, for instance, the YUCRG study of Category T3 NXMX (UICC 1974) bladder cancer treated with radiotherapy D.O.X. and 5F.U. which was not attractive to the surgeons in the EORTC group, but those who have already taken SR units in their stride will no doubt clear these hurdles too.

Many of the older clinicians will feel that the medical oncologists risk losing credibility by making much out of minor remissions, but we must not forget that the same initial scepticism greeted chemotherapy for childhood malignancy and in this field it has now entirely changed the prospects for cure. We must continue to seek a similar outcome in bladder cancer.

\section{Childhood Diabetes and its Management}

By Oman Crisg. 2nd edn. Postgraduate Paediatric Series. General Editor, John Apley. Pp. xi +316 , illustrated. Butterworths, London, 1981. £17.50.

Diabetes in childhood is surrounded by controversy and dissent. Arguments are still waging over the necessity for strict dietary and blood glucose control, and over the composition of insulin types at each injection and even the number of injections per day. Dr Craig approaches the problems of diabetes in a refreshing and delightful way. The use of the first person singular in such an erudite publication makes for compelling reading, after the initial discomposure. Dr Craig covers many aspects of childhood diabetes ex- $c$ tensively and on many occasions volunters' personal experience and verbatim accounts, but the latter, although amusing, add little to the factual material of the book. Useful alternatives are given. However, at certain controversial points, such as the notoriously difficult treatment of $\bar{\sigma}$ the newly diagnosed mild diabetic and the use of intravenous $\bar{\sigma}$ insulin in ketoacidotic coma or pre-coma, either too little $\vec{\sigma}$ information is given or only one alternative offered. Certain $\varrho$ aspects, such as diet, insulin metabolism and antagonists are dealt with in thorough and commendable depth; however, other equally important points, such as behavioural pro- $\overrightarrow{0}$ blems, are superficially approached. The section on prog- $\overrightarrow{\vec{\omega}}$ nosis for adult life was most disconcerting as the author $\vec{\omega}$ appeared to advocate prognostication on the evidence of past experience, seemingly ignoring the rapidly advancing techniques and knowledge. Nevertheless, with these few reservations, the publication covers the large area of diabetes iv interestingly and comprehensively and contains a wealth of $V$ knowledge. It should appeal to and be useful for aspiring general and specialist paediatricians alike.

\section{Clinical Science for Surgeons}

Edited by William Burnett. Pp. xiv +849 , illustrated. O Butterworths, London, 1981. $£ 37.50$.

This volume is based on the requirements of the Part I Examination for the Fellowship of the Royal Australasian $\mathbb{D}$ College of Surgeons and concentrates on the physiology and $\mathbb{\varnothing}$ pathophysiology required for this examination together wit 3 relevant clinical details where appropriate and such anatomy as is necessary for a clear understanding of the other subjecto. Professor Burnett of Brisbane has brought together a team no less than 70 experts, mostly from Australia and $\mathrm{Ne}$ Zealand, which includes surgeons, anaesthetists, physiologist pathologists and basic scientists. In the first section of the book the basis of clinical science is covered from the physiology of the normal cell, through cell injury, inflammation, immunology and the fundamentals of metabolism. The second section considers the major systems of the body, while the third deals with the basic principles of surgical practice with emphasis on the pre-operative situation, events in the operating theatre, and problems arising postoperatively. Consideration is also given to allied disciplines and covers such subjects as the kinetics of drug therapy, the neurological mechanisms of pain and the essentials of statistics, computers and clinical trials.

Although it is a massive and heavy volume, it has been clearly produced, the text is pleasantly written and the illustrations (mostly in the form of clear line diagrams and charts) are helpful.

Although designed primarily for the Australian Examination, this is certainly a book that will be of value to both surgeons and anaesthetists studying for their preliminary examinations in this country as well as for practising clinicians.

\section{Curator of the Dead. Thomas Hodgkin 1798-1866}

By Michael Rose. Pp. 148, illustrated. Peter Owen, London, 1981. £9.50.

Thomas Hodgkin (1798-1866) was a remarkable eccentric who wore many different hats with equal distinction: pathologist, physician, museum curator, Quaker, slave trade abolitionist, co-founder of the Aborigines Protection Society and of the Ethnological Society, and member of the founding Senate of the University of London (1837-1866). These were but some of the crusades he pursued as a 'workaholic' bachelor during the first half of the 19th century. His \title{
政
}


immortality stems from an article he published in 1832 in the Journal of the Medical and Chirurgical Society entitled 'On some morbid appearances of the absorbent glands and spleen'. He described the gross pathological changes in 6 cases he had encountered at Guy's during his time as Curator of the Museum (1825-1837). This was a macroscopic description, for his microscope was a primitive combination of lenses developed by a London wine merchant, J. J. Lister (father of Sir Joseph Lister). In 1926 the pathological material from the 6 patients whom Hodgkin had described in 1832 were subjected to modern histology. Hodgkin's disease was confirmed in 3 , one had tuberculosis, another had syphilis, and a non-Hodgkin's lymphoma in the other. His other claim to fame as a doctor was that he introduced Laennec's stethoscope to London medical circles. Whilst still a medical student at Edinburgh, he went to Paris in 1821 for an overseas elective which lasted one year. He attended Laennec's lectures at Necker Hospital, and soon after his return to London he presented a paper on Laennec's stethoscope to Guy's Hospital Physical Society in October 1822.

Michael Rose, author of this delightful biography of Hodgkin, is a London haematologist and a Guy's man. He guides us through the medico-political intrigues behind Hodgkin's failure to become a consultant physician at Guy's in 1837, when his medical career came to an abrupt end. Following this setback he devoted his life to social reform. Dr Rose persuades the reader convincingly that Hodgkin's tragedy, perhaps, was that his standards in medicine and on issues of human rights were always in advance of his time.

When he was aged 51 years, Hodgkin married a widow with 2 grown-up sons, but he had no children of his own. His brother, John, had 12 children so we are fortunate to have several distinguished Hodgkins today.

This book is so enjoyable that you will not be able to put it down until you have finished it. The author maintains our interest throughout because he has researched his background data painstakingly and has a most polished, elegant style of authorship.

\section{Drug Reactions and the Liver}

Edited by Michael Davis, J. Michael Tredger and Roger Williams. Pp. xii +364 , illustrated. Pitman Medical, London, 1981. £20.00.

Adverse effects upon the liver are among the most important of drug reactions, and many of them are fatal, despite our better understanding of their nature and increasingly sophisticated methods of management. This volume, edited by the staff of the King's College Hospital Liver Unit, is the record of a symposium held in 1980 to review the pathogenesis and treatment of a variety of drug-induced liver disorders, including those due to paracetamol, halothane and oral contraceptives. Its production is excellent, and a particularly valuable feature is the edited record of the discussions that took place, showing that there is still uncertainty over many issues which some of us thought were resolved long ago! This book represents a major milestone in clinical toxicology and should be readily available to all involved in clinical research.

\section{The Endometrium}

By W. B. Robertson. Pp. xii +201 , illustrated. Butterworths, London, Boston, 1981. £25.00.

This book is a volume of the publisher's Postgraduate Pathology Series and as such will have most immediate appeal to histopathologists who are required to deal with gynaecological specimens. However, Professor Robertson has succeeded in dealing with his subject in a very clinical way so that the result is also of great potential interest and benefit to the practising gynaecologist.

Following some introductory remarks the book deals with the appearances to be seen in normal endometrium and then with the detailed microscopical changes found in association with various abnormalities of the menstrual cycle. Chapter four discusses the changes of pregnancy, both normal and abnormal, and there follows detailed description of the changes of endometritis and of iatrogenic effects. The book ends with consideration of the features of neoplastic diseases of the endometrium.

Professor Robertson's writing is both interesting and informative as well as occasionally amusing and the excellent text is well illustrated with 213 photomicrographs. All the illustrations are in black-and-white but this seems to be no disadvantage since they are well chosen to illustrate the point under discussion. No references are provided within the text which will be a handicap to anyone wishing to pursue individual points but each chaper ends with a selected list for further reading and the author adds his own brief comment on each suggested item. There is a good index.

This is a book which should certainly find a useful place on the microscope bench of any gynaecological histopathologist but it would also be of interest and value to most clinical gynaecologists both in improving the quality of information provided with requests for examination of specimens and by helping to elucidate the implications of the resulting reports. It is unfortunate that the price, presumably the result of the necessarily large number of photographic blocks, may deter some potential purchasers.

\section{A Handbook of Obstetrics and Gynaecology for the House Officer}

By Mary M. Anderson. Pp. 174. Faber and Faber, London, 1981. £3.95.

This book is intended to be carried in the pocket of the new houseman in obstetrics or gynaecology to provide him with a source of instant advice on the various problems which may confront him in his day-to-day work. As such it makes no attempt to provide more than the basic practical requirements and those requiring further information will need to refer to the standard textbooks on the subjects.

The practical aspects of work in the antenatal clinic and ward, the labour ward and the postnatal ward and the clinic are each dealt with in turn and the obstetric section ends with a useful chapter on the assessment and management of the neonate. The gynaecological section also deals with clinic and ward work and then goes on to advise about gynaecological emergencies and certain practical procedures and includes short sections on contraception and on the social and legel aspects.

In any book of this sort there will always be occasional subjects which some would omit and others would include but I was surprised to find no mention of termination of pregnancy by prostaglandins, a procedure which many housemen may need to know. I should also like to have seen rather more discussion of alternative forms of contraception so that the houseman is properly equipped to discuss the various pros and cons with his patients (all the 'recommended' methods are well covered but there is no mention, for example, of coitus interruptus.)

This book succeeds in remaining suffiziently general in its advice to be readily adaptable to the routines in most units and it should provide useful guidance as to the procedure to be followed in situations where the new resident may yet need to have practical advice from his more senior colleagues. 